\title{
QTL Mapping of Adult-Plant Resistance to Leaf and Stripe Rust in Wheat Cross SW 8588/Thatcher using the Wheat 55K SNP Array
}

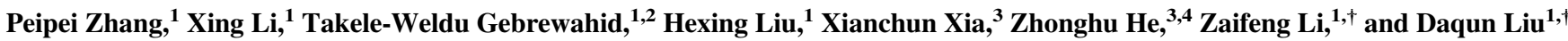 \\ ${ }^{1}$ College of Plant Protection, Hebei Agricultural University, Baoding, Hebei 071001, China \\ ${ }^{2}$ College of Agriculture, Aksum University, Shire-Indaslassie, Tigray 314, Ethiopia \\ ${ }^{3}$ Institute of Crop Science, National Wheat Improvement Center, Chinese Academy of Agricultural Sciences (CAAS), Beijing \\ 100081, China \\ ${ }^{4}$ International Maize and Wheat Improvement Center (CIMMYT) China Office, Beijing 100081, China
}

\begin{abstract}
Wheat leaf rust (caused by Puccinia triticina) and stripe rust (caused by Puccinia striiformis f. sp. tritici) cause large production losses in many regions of the world. The objective of this study was to identify quantitative trait loci (QTL) for resistance to leaf rust and stripe rust in a recombinant inbred line population derived from a cross between wheat cultivars SW 8588 and Thatcher. The population and parents were genotyped with the Wheat 55K SNP Array and SSR markers and phenotyped for leaf rust severity at Zhoukou in Henan Province and Baoding in Hebei Province. Stripe rust responses were also evaluated at Chengdu in Sichuan Province, and at Baoding. Seven and six QTL were detected for resistance to leaf rust and stripe rust, respectively. Four QTL on chro-

that was previously thought to be ineffective in China, contributed a large effect for leaf rust resistance. QLr.hebau-5AL/QYr.hebau-5AL, QLr. hebau-3BL, QLr.hebau-6DS, QYr.hebau-4BS, and QYr.hebau-6DS are likely to be new QTL, but require further validation. Kompetitive allelespecific PCR (KASP) markers for QLr.hebau-2DS and QLr.hebau$5 A L / Q Y$ r.hebau- $5 A L$ were successfully developed and validated in a diverse wheat panel from Sichuan Province, indicating their usefulness under different genetic backgrounds. These QTL and their closely linked SNP and SSR markers will be useful for fine mapping, candidate gene discovery, and marker-assisted selection in breeding for durable resistance to both leaf and stripe rusts.
\end{abstract} mosomes 1BL, 2AS, 5AL, and 7BL conferred resistance to both rusts. The QTL on 1BL and 2AS were identified as Lr46/Yr29 and Lr37/ Yr17, respectively. QLr.hebau-2DS from Thatcher, identified as $L r 22 b$
Keyword: disease management, cultivar/resistance, field crops, cereals and grains, fungi
Leaf rust (or brown rust) caused by Puccinia triticina Erikss. (Pt) and stripe rust (or yellow rust) caused by Puccinia striiformis Westend. f. sp. tritici Erikss. (Pst) are important diseases of wheat worldwide. Leaf rust can cause yield losses of up to $40 \%$ under favorable conditions (Knott 1989). Leaf rust epidemics in China in 1969, 1973, 1975, 1979, and 2012 caused significant yield losses (Zhou et al. 2013). Stripe rust remains a significant threat in the majority of wheat growing regions throughout the world with the potential to inflict regular regional crop losses ranging from 0.1 to $5 \%$, with rare events giving losses of 5 to $25 \%$ or more (Wellings 2011). Since the 1950 s, stripe rust epidemics in China occurred at least in 15 crop seasons, and losses exceeding one million tons were recorded in four of those years (Wan et al. 2007). Although wheat rusts can be managed by using fungicides, growing resistant cultivars is a more efficient, economic, and environmentally friendly way to minimize losses (Singh et al. 2013).

Resistance to wheat rusts is generally classified into two types, race specific and race nonspecific. Race specific resistance is often controlled by a single gene that starts expressing at the seedling stage

${ }^{\dagger}$ Corresponding authors: Z. Li; 1zf7551@aliyun.com;

D. Liu; 1dq@ hebau.edu.cn

Peipei Zhang and Xing Li contributed equally to this work.

Funding: This study was supported by National Natural Science Foundation of China (31361140367, 31571662, and 31601299).

*The $\boldsymbol{e}$-Xtra logo stands for "electronic extra" and indicates that nine supplementary tables are published online.

The author(s) declare no conflict of interest.

Accepted for publication 3 July 2019.

(C) 2019 The American Phytopathological Society but remains effective throughout all growth stages (all-stage resistance). However, race specific resistance may lose effectiveness when virulent races arise. For example, significant yield losses occurred in China in the 1980s and early 1990s when Pst races virulent to resistance gene $\mathrm{Yr} 9$ that was in many widely grown wheat cultivars became predominant (Xie et al. 1990). Race nonspecific resistance tends to be controlled by polygenes and usually expresses quantitatively at postseedling stages, generally described as adult plant resistance (APR). The advantage of this type of resistance is its reputed durability (Johnson 1988).

So far, $79 \mathrm{Lr}$ genes for leaf rust resistance and $81 \mathrm{Yr}$ genes for stripe rust resistance have been permanently named in wheat (McIntosh et al. 2017; Qureshi et al. 2018). Three loci, namely Lr34/Yr18/ Pm38/Sr57 (Lagudah 2011), Lr46/Yr29/Pm39/Sr58 (Lagudah 2011), and Lr67/Yr46/Pm46/Sr55 (Herrera-Foessel et al. 2014), have been reported to be durable, race nonspecific APR to leaf rust, stripe rust, stem rust, and powdery mildew. The individual effects of these pleiotropic APR genes are low or moderate, but when they are combined with other genes, high levels of resistance can be achieved (Singh et al. 2000). In addition to the formally named genes, more than 80 leaf rust and 140 stripe rust resistance genes or QTL have been reported (Li et al. 2014; Rosewarne et al. 2013). However, some of the genes or QTL may be redundant.

Molecular markers are widely used to map resistance genes. For many years, SSR markers were widely used for linkage mapping due to their advantages of codominance, high accuracy, high repeatability, high polymorphism, chromosome specificity, and ease of manipulation (Röder et al. 1998). However, high-density single nucleotide polymorphism (SNP) markers using gene-chip technology now provide a superior approach for QTL mapping due to reduced errors in evaluation, greater accuracy, and particularly greater density than previous systems (Yu et al. 2011). Several SNP arrays for wheat are available, such as $9 \mathrm{~K}, 90 \mathrm{~K}, 35 \mathrm{~K}, 660 \mathrm{~K}$, and 820K (Allen et al. 2017; Cavanagh et al. 2013; Cui et al. 2017; Wang et al. 2014; Winfield et al. 2016). The wheat $660 \mathrm{~K}$ SNP that is efficient for constructing high-density wheat genetic 
maps has the advantage of greater marker density and greater resolution as well as better distribution across chromosomes compared with the earlier 90K SNP chip (Cui et al. 2017). The wheat 55K SNP array consists of SNPs carefully selected from the 660K SNP chip with the features of lower cost, high accuracy, and medium but acceptable density (http://www.capitalbiotech.com/). These SNPs distribute uniformly in all 21 wheat chromosomes with about 2,600 SNP on each chromosome at an average physical distance smaller than $300 \mathrm{~kb}$.

Wheat line SW 8588 (Milan'S'/SW 5193) developed by the Sichuan Academy of Agricultural Science has high levels of resistance to leaf and stripe rust in the field. Thatcher, bred by the Minnesota Agricultural Experiment Station and the Division of Cereal Crops and Diseases of U.S. Department of Agriculture (Hayes et al. 1936), is commonly used as a susceptible check for leaf rust research. Almost all widely distributed near-isogenic lines for leaf rust resistance genes were developed in the Thatcher background by scientists in Canada (McIntosh et al. 1995). The objective of this study was to determine the genetic basis of resistance to leaf rust and stripe rust in SW 8588 using a recombinant inbred line (RIL) population of SW 8588 crossed with Thatcher.

\section{Materials and Methods}

Plant materials and races. A total of $144 \mathrm{~F}_{6}$ RILs derived from cross SW 8588/Thatcher were used to map genes/QTL for resistance to leaf and stripe rust. Thirty-six lines with known leaf rust resistance genes and $14 P t$ races were used in multirace comparisons for leaf rust in seedling stage tests in a greenhouse. Twenty wheat lines for differentiating Pst races in China and six Pst races were used in seedling tests for stripe rust reactions. Four $P t$ races (THJS, PGTS, THND, and PHTT) and three Pst races (CYR32, CYR33, and CYR34) were used to test the RILs in the fields. The $P t$ races and 36 wheat lines with known $L r$ genes were from the Biological Control Center for Plant Diseases and Plant Pests of Hebei, Hebei Agricultural University. The Pst races and 20 wheat differential lines were kindly provided by the Institute of Plant Protection, Chinese Academy of Agricultural Sciences, Beijing. In addition, a panel consisting of 60 diverse wheat cultivars (lines) from Sichuan Province was used for QTL validation (Supplementary Table S1).

Evaluation of seedling responses to leaf and stripe rust in the greenhouse. SW 8588, Thatcher, Zhengzhou 5389, and the 36 lines with known $L r$ genes were tested using $14 P t$ races for comparison of leaf rust infection types (IT). SW 8588, Thatcher, Mingxian 169, and the 20 Chinese differentials were tested for stripe rust ITs using six Pst races. Eight to ten seeds of each genotype were planted in a $12 \times 6$ multicell plastic tray $(3.8 \times 28.4 \times 53.8 \mathrm{~cm})$. Inoculations were performed at the two-leaf stage by spraying urediniospores suspended in light-weight mineral oil at a concentration of 2 to $3 \mathrm{mg} / \mathrm{ml}$ using an atomizer $(64 \times 51 \times 33 \mathrm{~cm}, 1.5 \mathrm{~L}$, PezinYL Co. Ltd., Yiwu, China) onto the seedlings. Inoculated plants were placed in plasticcovered cages at $18^{\circ} \mathrm{C}$ for leaf rust and $10^{\circ} \mathrm{C}$ for stripe rust and $100 \%$ relative humidity (RH) for approximately $24 \mathrm{~h}$ in darkness and then transferred to a greenhouse maintained with $12 \mathrm{~h}$ light and $12 \mathrm{~h}$ dark at 22 to $25^{\circ} \mathrm{C}$ for leaf rust and 18 to $22^{\circ} \mathrm{C}$ for stripe rust. Infection types were recorded 2 weeks after inoculation. Leaf rust was evaluated according to the Stakman 0 to 4 scale as modified by Roelfs et al. (1992), where $0=$ immune, ; = hypersensitive flecks with necrosis, $1=$ small uredinia surrounded by necrosis, $2=$ small to medium uredinia surrounded by necrosis, $X=$ heterogeneous, similarly distributed over the leaves, $3=$ moderate size uredinia that may be associated with chlorosis, $4=$ large uredinia without chlorosis, $+=$ uredinia somewhat larger than normal, $-=$ uredinia somewhat smaller than normal, and $\mathrm{C}=$ more chlorosis than normal. Numbers 0 to 2 and $X$ were designated as resistant and 3 to 4 as susceptible. For stripe rust, ITs were recorded according to the 0 to 9 scale as modified by $\mathrm{McNeal}$ et al. (1971), where $0=$ no visible infection; $1=$ necrotic/ chlorotic flecks without sporulation; 2 = necrotic/chlorotic blotches/ stripes without sporulation; $3=$ necrotic/chlorotic blotches/stripes with trace sporulation; $4=$ necrotic/chlorotic blotches/stripes with light sporulation; $5=$ necrotic/chlorotic blotches/stripes with intermediate sporulation; $6=$ chlorotic stripes with moderate sporulation; 7 = stripes without chlorosis/necrosis and with moderate sporulation; $8=$ stripes without chlorosis/necrosis and with sufficient sporulation; and $9=$ stripes without chlorosis/necrosis and abundant sporulation. Lines with IT 0 to 4, 5 to 6 , and 7 to 9 are categorized as resistant, intermediate, and susceptible, respectively. Tests were conducted in two replications, but IT data from only one test is reported because of the lack of significant variation in both tests.

Field experiments. The RIL population and parents were grown at Baoding in Hebei Province in the 2015/2016 and 2016/2017 cropping seasons, and at Zhoukou in Henan Province in the 2015/2016 cropping season for evaluation of leaf rust response (environments hereinafter referred to as 16BDLR, 17BDLR, and 16ZKLR). Both Baoding and Zhoukou are leaf rust hotspot regions. Stripe rust phenotyping was made at Chengdu (Sichuan Province) in the 2014/2015 and 2015/2016 growth seasons, and at Baoding in 2015/2016 and 2016/2017 (15CDYR, 16CDYR, 16BDYR, and 17BDYR). Chengdu is a hotspot region for stripe rust, while Baoding is not a major stripe rust region as the temperatures at the late growth stages are usually not favorable for stripe rust development. The field trials were conducted in randomized complete blocks with two replicates. Each plot consisted of a single $1.5 \mathrm{~m}$ row with $30 \mathrm{~cm}$ between rows. Approximately 60 seeds were sown in each plot. Every tenth row was followed by rows of the highly susceptible line Zhengzhou 5389 as a control and spreader for leaf rust or Mingxian 169 for stripe rust. Spreader rows were also planted surrounding the plots. Leaf rust epidemics were initiated by inoculating the spreader rows with a water suspension of urediniospores of equal amounts of $P t$ races THJS, PGTS, THND, and PHTT with a concentration 2 to $3 \mathrm{mg} / \mathrm{ml}$ added with a few drops of Tween $20(0.03 \%)$ at the early jointing stage (Zadoks growth stage 30; Zadoks et al. 1974) using an atomizer. These four $P t$ races were virulent on seedlings of SW 8588. Similarly, spore suspensions prepared by equal quantities of urediniospores of Pst races CYR32, CYR33, and CYR34 (Zhang et al. 2012) were sprayed onto plants in the spreaders for stripe rust evaluation. Disease severity was recorded two or three times at weekly intervals with the first scoring 4 weeks after inoculation. Disease severity data (0 to $100 \%$ ) were recorded as percentage of leaf area covered with uredinia or necrotic stripes according to the modified Cobb scale (Peterson et al. 1948) where $0 \%=$ immune, and $100 \%=$ fully susceptible. Maximum disease severity (MDS, \%) was used for QTL analysis. Correlation analysis between MDS in different environments was conducted using bivariate two-tailed Pearson's correlation coefficients by IBM SPSS Statistics 21.0 (IBM Corp., Armonk, NY). Analysis of variance (ANOVA) was performed using the generalized linear model of SPSS. Cultivars, environments (the combination of location and year), and their interaction were treated as fixed effects, and replications nested in environments were set as random.

Linkage map construction. Genomic DNA was extracted from noninfected seedlings of the parents and RILs using the Cetyltrimethylammonium Bromide (CTAB) method (Sharp et al. 1988). DNA concentration was measured using a Thermo Scientific NanoDrop 2000. DNA samples of the 144 RILs and parents were genotyped with the Affymetrix 55K SNP Array (53,064 markers) by CapitalBio Technology Company (Beijing, China). SNPs with $>20 \%$ missing data were removed. Twelve SSR markers were also used to genotype the entire population. Linkage maps were constructed using the MAP function in IciMapping 4.1 (http://www.isbreeding.net/software/? type $=$ detail\&id=18, Li et al. 2007), and algorithm of groups ordered "nnTwoOpt" using the Kosambi map function to obtain map distances from recombination frequencies (Kosambi 1943). The criterion and window size for Rippling were "SARF" and "5," respectively. Linkage maps were graphically visualized with MapChart 2.3 (Voorrips 2002).

QTL detection. QTL analysis was conducted with the ICIMADD function using software IciMapping 4.1 (Li et al. 2007). Through 1,000 permutations at $P=0.01$, a logarithm of odds (LOD) threshold of 2.5 was set to declare significant QTL. Stepwise regression was used to detect the percentages of phenotypic variance explained (PVE, $R^{2}$ ) by individual QTL and additive effects at the 
LOD peaks. QTL identified in individual environments within overlapping $20 \mathrm{cM}$ (centimorgan) intervals were considered to be the same.

KASP assays and QTL validation using selected RILs and a diverse bread wheat panel. SNP markers highly associated with a specific QTL were converted to KASP markers using PolyMarker (Ramirez-Gonzalez et al. 2015). KASP assays were performed in a S1000 Thermal Cycler (Bio-Rad, Hercules, CA, U.S.A.). Reaction mixtures consisted of final volumes of $5 \mu$ l containing $2.5 \mu \mathrm{l}$ of $2 \times$ KASP V4.0 Mastermix (LGC Genomics), $0.056 \mu$ of assay primer mix $(12 \mathrm{mM}$ of each allele-specific primer and $30 \mathrm{mM}$ of common primer), and 50 to $100 \mathrm{ng}$ of genomic DNA. The cycling conditions were as follows: $94^{\circ} \mathrm{C}$ for $15 \mathrm{~min}, 9$ cycles of $94^{\circ} \mathrm{C}$ for $20 \mathrm{~s}$, touchdown starting at $65^{\circ} \mathrm{C}$ for $60 \mathrm{~s}$ (decreasing $0.8^{\circ} \mathrm{C}$ per cycle), 32 cycles of $94^{\circ} \mathrm{C}$ for $20 \mathrm{~s}$, and $57^{\circ} \mathrm{C}$ for $60 \mathrm{~s}$. The end-point fluorescence data were visualized with a microplate reader (FLUOstar Omega, BMG LABTECH, Germany) and analyzed by Klustering Caller software (LGC Genomics). Only the KASP markers showing the same segregation as the corresponding SNP markers in the parents and the RIL population were used to screen the diverse bread wheat genotypes. Independent-sample $t$ test was carried out using SPSS 21.0 to compare the positive and negative alleles' effect of the stable QTL on leaf rust and stripe rust based on the phenotypic data using the diverse bread wheat panel.

\section{Results}

Seedling response to leaf and stripe rust in the greenhouse. Reactions to the $14 P t$ races in the seedling tests are presented in Supplementary Table S2. SW 8588 showed resistance to nine $P t$ races (KHSS, FHJS, FGHQ, FHTS, HHTS, FHTT, FHKS, KHKQ, and FHSS). Eight of nine races were avirulent to $L r l$, indicating that SW 8588 contained Lrl. Lrl in SW 8588 was confirmed by the presence of diagnostic molecular marker WR003. The seedling reactions to stripe rust are presented in Supplementary Table S3. SW 8588 was susceptible to four Pst races, Gn22-1, CYR32, CYR33, and CYR34, and resistant to $P$ st race Sull. SW 8588 showed a similar IT to stripe rust with the $Y r 17$ line, indicating that SW 8588 might contain $Y r 17$. Both SW 8588 and Thatcher showed susceptible ITs to the four Pt races (THJS, PGTS, THND, and PHTT) and three Pst races (CYR32, CYR33, and CYR34) used in the field tests at the seedling stage.

Field testing. The mean leaf rust MDS scores of SW 8588 and Thatcher were 3.7 and $76.7 \%$, respectively, and mean leaf rust severity scores on the RILs ranged from 23.0 to $44.9 \%$ in the three environments (Table 1). The distribution of mean leaf rust MDS frequencies for the population was continuous, indicating quantitative inheritance (Fig. 1). The mean MDS scores for response to stripe rust in SW 8588 and Thatcher were 3 and 95\%, respectively. The mean MDS scores for the RILs were 38.0 and $43.3 \%$ in 15CDYR and 16CDYR, respectively. However, in Baoding the mean MDS scores for SW 8588 and Thatcher were only 1 and 35\%, respectively. The mean MDS scores for the entire population were $11.9 \%$ in 16BDYR and 9.9\% in 17BDYR. The stripe rust MDS scores for the 144 RILs across all environments showed continuous distributions, also indicating quantitative inheritance.
Maximum disease severity scores for leaf rust across the three environments were significantly correlated with coefficients ranging from 0.71 to $0.74(P<0.001)$ (Table 2). For stripe rust, 15CDYR and 16CDYR were significantly correlated with a coefficient of $0.74(P<0.001)$. The coefficient for 16BDYR and 17BDYR was $0.64(P<0.001)$. However, the coefficient of correlation for 15CDYR and 17BDYR was low at $0.21(P<0.05)$ (Table 2). The coefficients of correlation between stripe rust and leaf rust disease scores were 0.37 to 0.54 across experiments. ANOVA confirmed significant variation among the genotypes, environments, and genotype $\times$ environment for both leaf rust and stripe rust (Supplementary Tables S4 and S5).

Linkage map construction. After removing monomorphic markers and those with missing data $>20 \%$ or distorted segregation, 8,755 (16.5\%) SNP markers remained, with 2,883 for the A genome, 4,330 for the B genome, and 1,542 for the D genome. These SNP markers and 12 SSR markers were used to construct genetic linkage maps that covered 2,152.23 cM, 1,614.11 cM, and 1,721.99 cM for genomes $\mathrm{A}, \mathrm{B}$, and $\mathrm{D}$, with average marker densities of $0.75,0.37$, and $1.12 \mathrm{cM} /$ marker, respectively (Supplementary Table S6).

QTL mapping of rust resistance. Four possible pleiotropic rust resistance QTL from SW 8588 were detected in the SW 8588/ Thatcher RIL population (Table 3). The first QTL, QLr.hebau$1 B L / Q Y$ r.hebau-1BL, detected in two leaf rust environments and
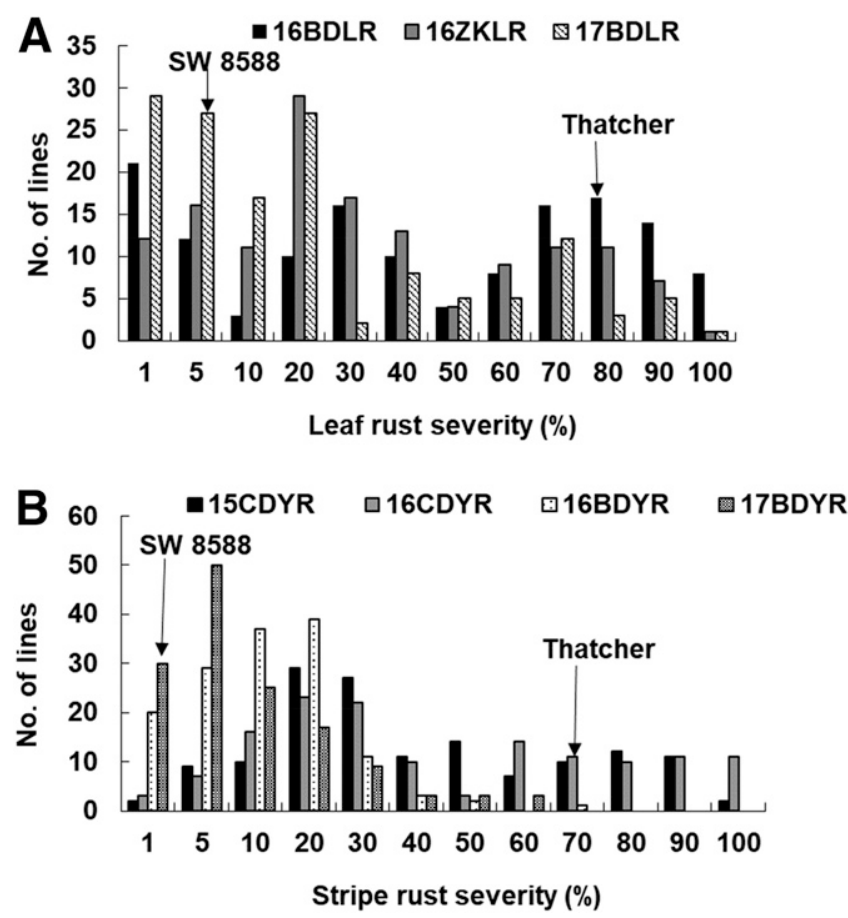

Fig. 1. Frequency distributions of SW $8588 \times$ Thatcher recombinant inbred lines for final severity of leaf rust $(\mathbf{A})$ and stripe rust $(\mathbf{B})$ in field trials. Mean values for parents SW 8588 and Thatcher are indicated by arrows.

Table 1. Summary of maximum disease severity in the SW $8588 \times$ Thatcher recombinant inbred lines population phenotyped for leaf and stripe rust responses

\begin{tabular}{|c|c|c|c|c|c|c|c|}
\hline \multirow[b]{2}{*}{ Parameter } & \multicolumn{3}{|c|}{ Leaf rust maximum disease severity } & \multicolumn{4}{|c|}{ Stripe rust maximum disease severity ${ }^{\mathrm{z}}$} \\
\hline & 16BDLR & 16ZKLR & 17BDLR & 15CDYR & 16CDYR & 16BDYR & 17BDYR \\
\hline SW 8588 & 5.0 & 1.0 & 5.0 & 1.0 & 5.0 & 1.0 & 1.0 \\
\hline Thatcher & 80.0 & 80.0 & 70.0 & 100.0 & 90.0 & 30.0 & 40.0 \\
\hline Population mean & 44.9 & 33.4 & 23.0 & 38.0 & 43.3 & 11.9 & 9.9 \\
\hline Lowest MDS & 1.0 & 1.0 & 1.0 & 1.0 & 1.0 & 1.0 & 1.0 \\
\hline Highest MDS & 100.0 & 100.0 & 100.0 & 100.0 & 100.0 & 70.0 & 60.0 \\
\hline
\end{tabular}

y 16BDLR, 17BDLR, and 16ZKLR: the MDS for leaf rust in 2015/2016 and 2016/2017 cropping seasons at Baoding in Hebei Province, and Zhoukou in Henan Province during the 2015/2016 cropping season.

z 15CDYR, 16CDYR, 16BDYR, and 17BDYR: the MDS for stripe rust in 2014/2015 and 2015/2016 cropping seasons at Chengdu in Sichuan Province, and Baoding in Hebei during the 2015/2016 and 2016/2017 cropping seasons. 
two stripe rust environments, explained $12.6-14.1 \%$ and $13.7-17.5 \%$ of the phenotypic variances for leaf rust and stripe rust, respectively (Table 3; Fig. 2). The second QTL, located on chromosome 2AS, was identified as $L r 17 / \operatorname{Yr} 37$ based on the presence of marker VENTRIUP-LN2. $L r 17 / Y r 37$ explained $8.9-10.9 \%$ and $9.2-16.8 \%$ of the phenotypic variances for leaf rust and stripe rust, respectively, and it was stable across environments for both diseases (Table 3; Fig. 2). The third potentially pleiotropic QTL was $Q L$ r.hebau-5AL/QYr.hebau-5AL detected in 2016ZKLR, 2017BDLR, and 2016CDYR. This QTL had a relatively minor effect on disease response and explained $6.6-7.1 \%$ and $9.1 \%$ of the variation for leaf rust and stripe rust, respectively (Table 3; Fig. 2). The fourth potentially pleiotropic rust resistance QTL, QLr.hebau-7BL/QYr.hebau-7BL, again with a minor effect, was linked with Xcfa2040, and explained 18.4 and $5.9 \%$ of the phenotypic variances in 17BDLR and 16CDYR, respectively (Table 3; Fig. 2).

Three additional leaf rust APR QTL were detected on chromosomes 2DS, 3BL, and 6DS (Table 3; Fig. 2). QLr.hebau-2DS with the resistance allele from Thatcher was detected in all leaf rust tests. It was flanked by markers $A X-111031419$ and $A X-109507893$ and explained $11.3-23.7 \%$ of the variation across the environments.
QLr.hebau-3BL with its resistance allele from SW 8588 was detected only in 16BDLR and explained $5.6 \%$ of the phenotypic variances. $Q L r . h e b a u-6 D S$ from Thatcher, flanked by $A X-86175025$ and $A X$ 108780681 , was detected only in 16ZKLR with $6.3 \%$ phenotypic variance explained (PVE).

QYr.hebau-4BS and QYr.hebau-6DS were also identified in single environments. QYr.hebau-4BS from Thatcher was detected in 16CDYR with a PVE of 5.5\%. QYr.hebau-6DS from SW 8588 was detected in 17BDYR with a PVE value of 9.3\%. The QTL detected in this study with their flanking markers and physical positions are listed in Supplementary Table S7.

Average effects of leaf rust and stripe rust resistance QTL. The average effects of QTL for resistance to each disease were estimated in +QTL RILs and -QTL RILs based on closely linked markers (Fig. 3; Table 4). QLr.hebau-1BL/QYr.hebau-1BL contributed to resistance by reducing leaf rust severity in three environments by $14.0-20.5 \%$ and stripe rust severity at the two Chengdu environments (16CDYR and 17CDYR) by 23.1 and $24.5 \%$. Lr37/Yr17 reduced mean leaf rust and stripe rust severity by $13.9-18.2 \%$ and 6.1-22.9\%, respectively (Table 4). QLr.hebau-5AL and QYr.hebau$5 A L$ gave detectable reductions only in 16HNLR and 15CDYR,

Table 2. Pearson correlation coefficients (r) for two-way comparisons of leaf and stripe rust severity data from different environments

\begin{tabular}{|c|c|c|c|c|c|c|}
\hline Environment $^{\mathbf{y}}$ & 16BDLR ${ }^{\mathrm{z}}$ & 16ZKLR & 17BDLR & 15CDYR & 16CDYR & 16BDYR \\
\hline 16ZKLR & $0.74 * *$ & & & & & \\
\hline 17BDLR & $0.72 * *$ & $0.71 * *$ & & & & \\
\hline 15CDYR & $0.41 * *$ & $0.39 * *$ & $0.37 * *$ & & & \\
\hline 16CDYR & $0.51 * *$ & $0.50 * *$ & $0.46^{* *}$ & $0.74 * *$ & & \\
\hline 16BDYR & $0.37 * *$ & $0.53 * *$ & $0.45 * *$ & $0.29 * *$ & $0.54 * *$ & \\
\hline 17BDYR & $0.48 * *$ & $0.43 * *$ & $0.54 * *$ & $0.21 *$ & $0.42 * *$ & $0.64 * *$ \\
\hline
\end{tabular}

y 16BDLR, 17BDLR, and 16ZKLR: the MDS for leaf rust in 2015/2016 and 2016/2017 cropping seasons at Baoding in Hebei Province, and Zhoukou in Henan Province during the 2015/2016 cropping season; 15CDYR, 16CDYR, 16BDYR, and 17BDYR: the MDS for stripe rust in 2014/2015 and 2015/2016 cropping seasons at Chengdu in Sichuan Province, and Baoding during the 2015/2016 and 2016/2017 cropping seasons.

$\mathrm{z} * * P<0.01, * P<0.05$.

Table 3. Quantitative trait locus/loci for maximum disease severity to leaf and stripe rust by ICIM in the recombinant inbred lines population derived from cross SW 8588/Thatcher

\begin{tabular}{|c|c|c|c|c|c|c|c|}
\hline QTL $^{\mathbf{u}}$ & Environment & $\operatorname{Pos}^{v}$ & Marker interval & LOD $^{\mathbf{w}}$ & $\operatorname{PVE}(\%)^{x}$ & Add $^{\mathbf{y}}$ & Contributing parent ${ }^{\mathrm{z}}$ \\
\hline \multirow[t]{2}{*}{ QLr.hebau-1BL } & 16ZKLR & 26 & $A X-89740962-A X-108930953$ & 6.5 & 12.6 & -10.3 & SW 8588 \\
\hline & 17BDLR & 26 & $A X-89740962-A X-108930953$ & 5.3 & 14.1 & -9.2 & \\
\hline \multirow[t]{2}{*}{ QYr.hebau-1BL } & 15CDYR & 29 & $A X-109299717-A X-109892648$ & 7.2 & 17.5 & -12.1 & SW 8588 \\
\hline & 16CDYR & 29 & $A X-109299717-A X-109892648$ & 7.1 & 13.7 & -11.7 & \\
\hline \multirow[t]{3}{*}{ QLr.hebau-2AS } & 16BDLR & 38 & Xcfd36-Xwms636 & 5.1 & 10.9 & -10.8 & SW 8588 \\
\hline & 16ZKLR & 32 & Xwmc407-Xbarc1138 & 4.8 & 8.9 & -8.9 & \\
\hline & 17BDLR & 32 & Xwmc407-Xbarc1138 & 4.1 & 10.8 & -8.3 & \\
\hline \multirow[t]{4}{*}{ QYr.hebau-2AS } & 15CDYR & 36 & Xwmc407-Xbarc1138 & 5.4 & 12.1 & -10.2 & SW 8588 \\
\hline & 16CDYR & 37 & Xbarc1138-Xcfd36 & 8.7 & 16.8 & -13.0 & \\
\hline & 16BDYR & 37 & Xbarc1138-Xcfd36 & 2.6 & 9.6 & -3.0 & \\
\hline & 17BDYR & 38 & Xcfd36-Xwms636 & 2.8 & 9.2 & -3.3 & \\
\hline \multirow{2}{*}{ QLr.hebau-5AL } & 16ZKLR & 252 & $A X-110679506-A X-110996595$ & 3.6 & 7.1 & -8.5 & SW 8588 \\
\hline & 17BDLR & 252 & $A X-110679506-A X-110996595$ & 3.0 & 6.6 & -7.8 & \\
\hline QYr.hebau-5AL & 16CDYR & 259 & $A X-110909761-A X-110957925$ & 4.9 & 9.1 & -11.5 & SW 8588 \\
\hline QLr.hebau-7BL & 17BDLR & 78 & $A X-110568331-X c f a 2040$ & 7.2 & 18.4 & -11.9 & SW 8588 \\
\hline QYr.hebau-7BL & 16CDYR & 82 & Xcfa2040-Xwmc273 & 3.2 & 5.9 & -7.7 & SW 8588 \\
\hline \multirow[t]{3}{*}{ QLr.hebau-2DS } & 16BDLR & 0 & $A X-111031419-A X-109507893$ & 10.6 & 23.7 & 16.0 & Thatcher \\
\hline & 16ZKLR & 0 & $A X-111031419-A X-109507893$ & 7.2 & 13.7 & 10.9 & \\
\hline & 17BDLR & 0 & $A X-111031419-A X-109507893$ & 4.4 & 11.3 & 8.3 & \\
\hline QLr.hebau-3BL & 16BDLR & 10 & $A X-111014259-A X-111534420$ & 2.8 & 5.6 & -7.8 & SW 8588 \\
\hline QLr.hebau-6DS & 16ZKLR & 82 & $A X-86175025-A X-108780681$ & 2.8 & 6.3 & 8.0 & Thatcher \\
\hline QYr.hebau-4BS & 16CDYR & 44 & $A X-109867593-A X-111641369$ & 3.2 & 5.5 & 8.5 & Thatcher \\
\hline QYr.hebau-6DS & 17BDYR & 112 & $A X-109915375-A X-95175830$ & 2.8 & 9.3 & -3.3 & SW 8588 \\
\hline
\end{tabular}

u QTL overlapping in the one-log support confidence intervals were assigned the same symbol.

$\checkmark$ Peak position in centimorgans from the first linked marker of the relevant linkage group.

${ }^{w}$ Logarithm of odds (LOD) score.

$x$ Percentages of phenotypic variance explained by individual QTL.

y Additive effect of resistance allele.

$\mathrm{z}$ Parent with the resistance allele. 
respectively (Table 4). Significant reductions in disease severity of 15.7 and $25.0 \%$ were made by QLr.hebau-7BL in environments 16BDLR and 17BDLR. QYr.hebau-7BL reduced stripe rust severity by $15.0 \%$ in 16CDYR and $10.6 \%$ in 15CDYR (Table 4 ). The mean MDS for QLr.hebau-2DS ranged from 1.0 to $70.0 \%$ (except for one line rated at 90\%) compared with 5.0-90.0\% without it (Fig. 3G), and $Q L$ r.hebau-2DS conferred a $23.5-37.1 \%$ reduction in leaf rust severity (Table 4).
KASP markers development and validation of the QTL effects using KASP markers in the bread wheat panel. Four and two SNP markers associated with QLr.hebau-2DS and QLr.hebau-5AL/QYr.hebau-5AL representing the peak or flanking markers for the identified QTL on these chromosomes, respectively, were successfully converted to KASP markers (Supplementary Table S8). All these KASP markers were successfully used to genotype the wheat cultivars/lines in the diverse wheat panel, and the allelic analyses were conducted based on
1B

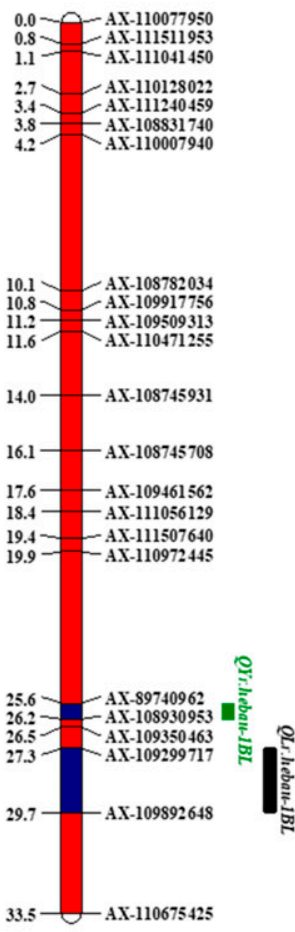

4B

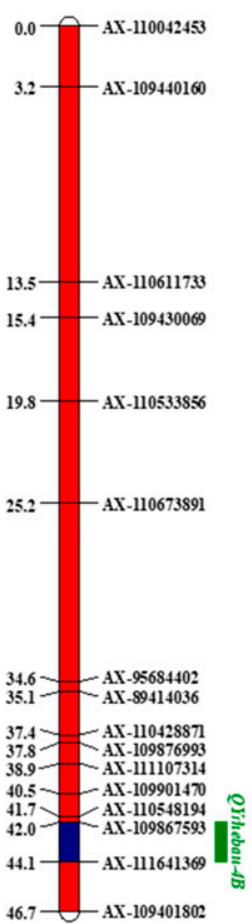

2A

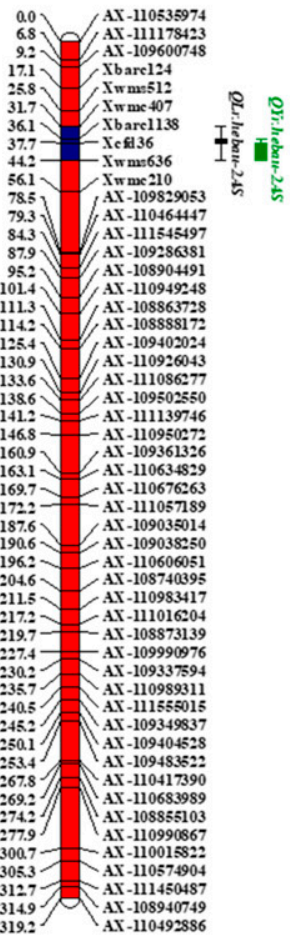

5A

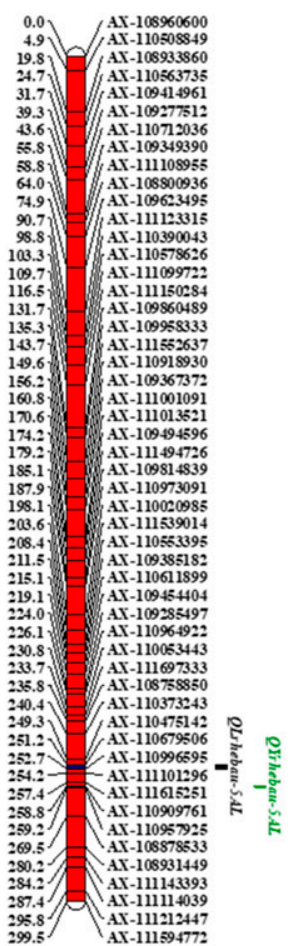

2D

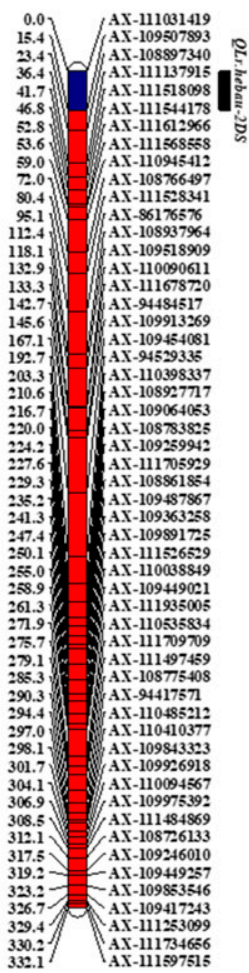

6D

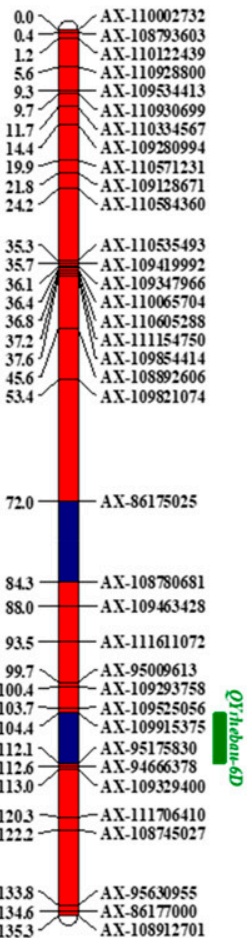

3B

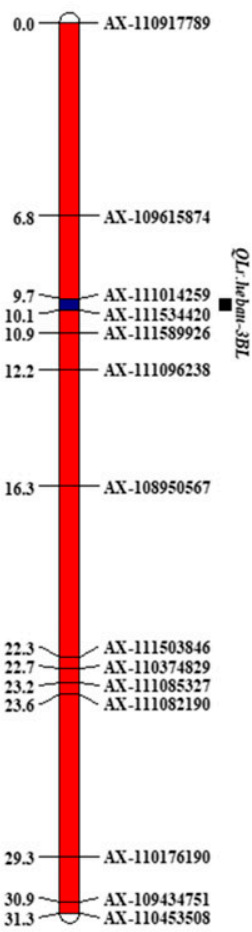

$7 \mathbf{B}$

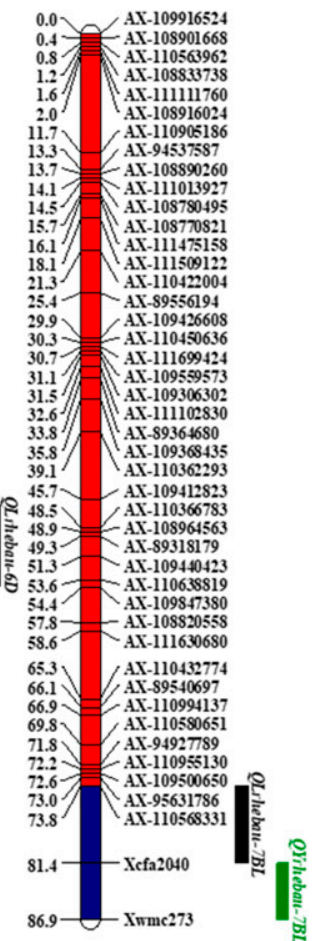

Fig. 2. Simplified genetic maps of seven chromosomes showing quantitative trait loci for leaf rust and stripe rust resistance in the SW 8588/Thatcher population. Lengths of chromosomes do not represent the same genetic distance. 
the field phenotyping data. The Student $t$ test indicated that MDS scores for the positive and negative alleles of both QLr.hebau-2DS and QLr.hebau-5AL/QYr.hebau-5AL showed significant differences at $P<0.05$ (Supplementary Table S9).

\section{Discussion}

Seven QTL for leaf rust resistance and six QTL for stripe rust resistance were detected in the current study. The total phenotypic variance explained by the QTL ranged from 40.2 to $61.2 \%$ across
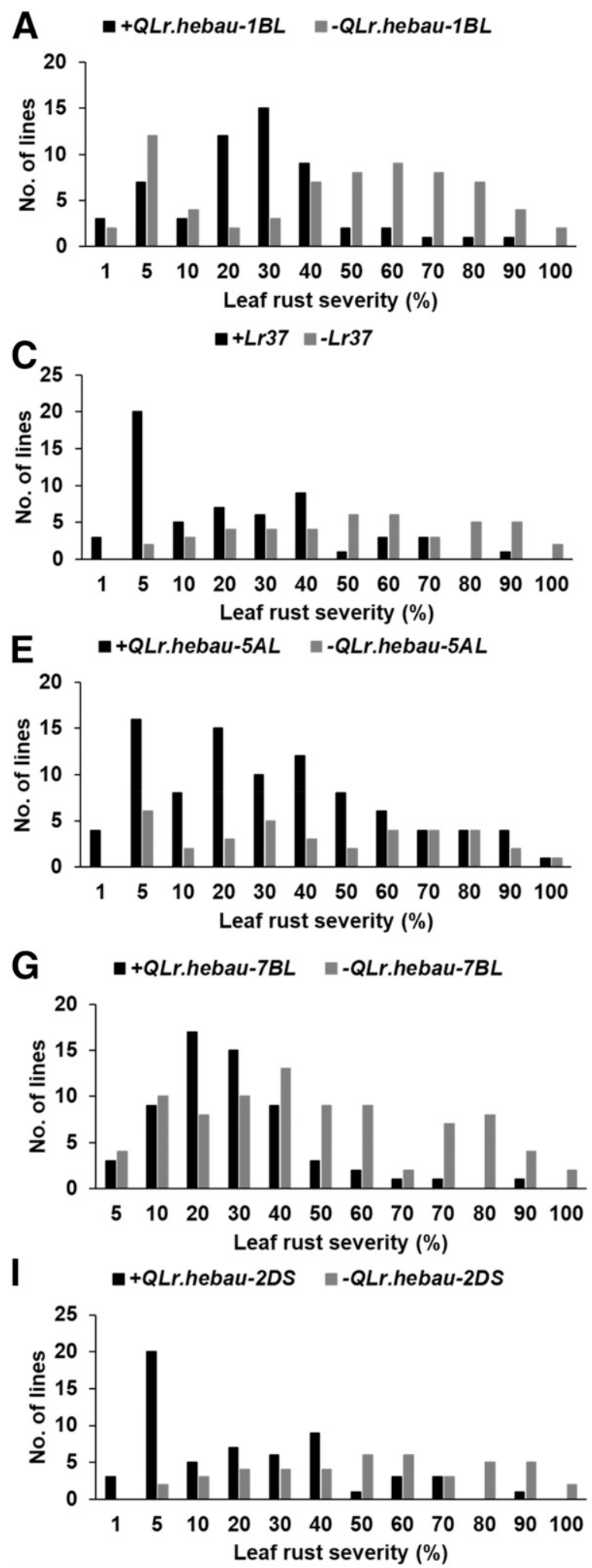

environments for leaf rust and 9.6-51.1\% across environments for stripe rust, confirming their significant effects in reducing disease severity. The relatively low correlation coefficients for stripe rust observed in Baoding and Chengdu might be due to different environments. The QTL detected in the study were compared with the known genes or QTL based on the chromosome position, molecular marker, pedigree, and resistance to rusts.

Based on the positions of closely linked markers, QLr.hebau-1BL/ QYr.hebau-1BL appeared to be the pleiotropic gene Lr46/Yr29. The
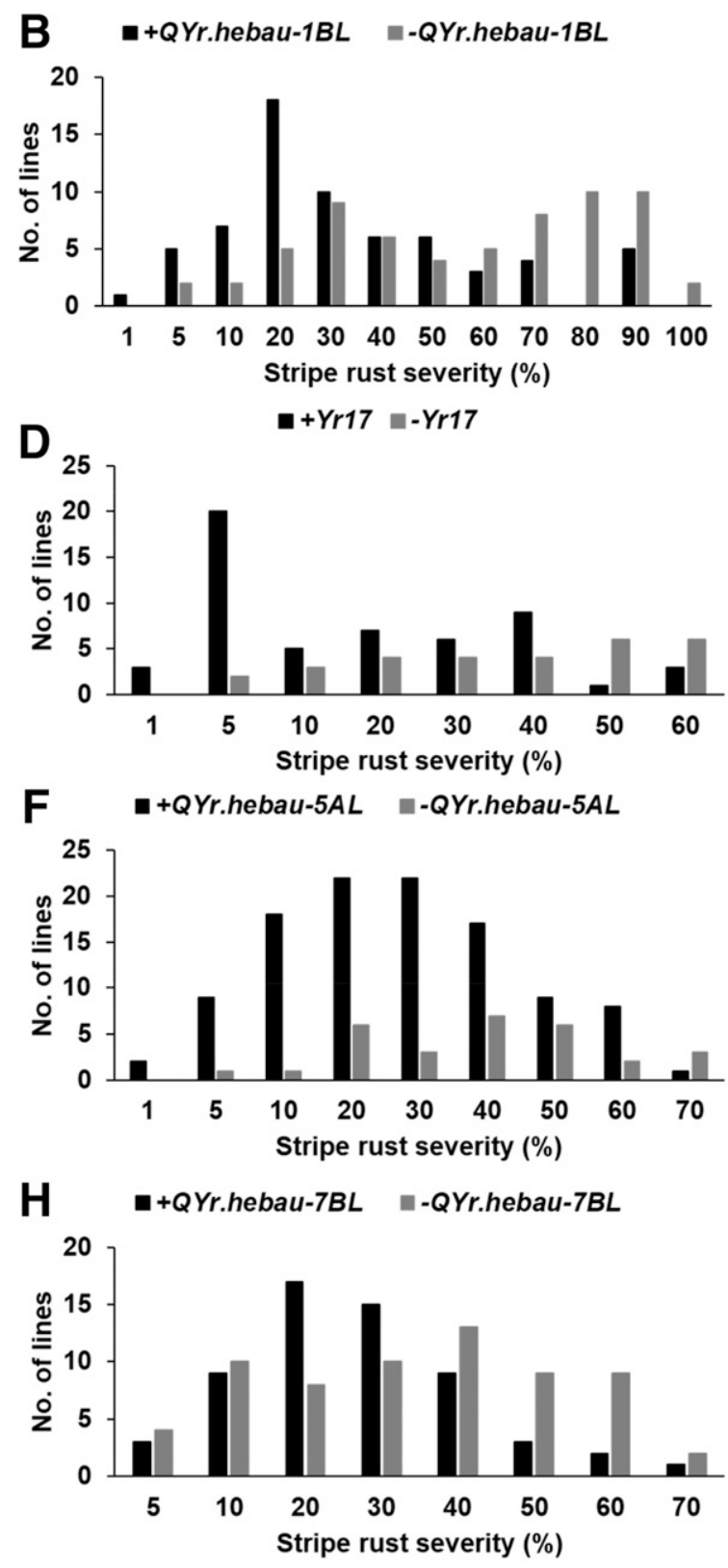

Fig. 3. Comparison of SW $8588 \times$ Thatcher recombinant inbred lines for mean maximum disease severity of leaf rust $(\mathbf{A}, \mathbf{C}, \mathbf{E}, \mathbf{G}$, and $\mathbf{I})$ and stripe rust $(\mathbf{B}$, D, F, and $\mathbf{H})$ in the presence or absence of each quantitative trait locus in field trials. 
result was also confirmed by gene-specific marker csLV46G22 kindly provided by Dr. E. S. Lagudah, CSIRO, Plant Industry, Canberra, Australia (data not presented).

SW 8588 is a derivative of the CIMMYT cultivar 'Milan' that carries a $2 \mathrm{~N}$ alien segment in chromosome $2 \mathrm{~A}$ (Cruz et al. 2016). That segment carries genes $\mathrm{Lr} 37$ and $\mathrm{Yr} 17$ for resistance to leaf rust and stripe rust, respectively (Bariana and McIntosh 1993). Since genes located in alien segments behave as linkage blocks in wheat backgrounds, these genes are likely to be at different loci rather than being pleiotropic. The QTL covering Yrl7 clearly conferred resistance in the current work despite the three Pst races having been documented as virulent for $\operatorname{Yr} 17$. This effect could be conferred by a linked gene in the translocated Aegilops vertricosa chromosomal segment for high-temperature adult-plant (HTAP) resistance as reported by Liu et al. (2018). The associated effect on leaf rust response indicated that Lr37 was effective. In another field test (unpublished data), the Thatcher NIL with the $2 \mathrm{~N}$ translocation (Lr37) produced a low reaction to a mixture of $P t$ races THJS, PGTS, THND, and PHTT, confirming that $\operatorname{Lr} 37$ behaved as an APR gene. Whereas some $\operatorname{Yr} 17-$ avirulent isolates are easily confirmed in seedling tests, others give ambivalent responses; hence reports of virulence should be checked by adult plant tests with relevant controls (Milus et al. 2015), as $\mathrm{Yr} 17$ is linked to a HTAP resistance QTL (Liu et al. 2018). The finding of significant contributions to resistance to both diseases in this study indicates that both $\operatorname{Yrll}$ (and/or the HTAP resistance QTL) and Lr37 were effective in our tests. If respective virulences were present in the mixed inoculum used to induce epidemics, then either of the virulent components were not present in adequate quantities to overcome the resistance genes. Otherwise, combinations of these genes and others conferred resistance in the lines. $\operatorname{Lr} 37 / \mathrm{Yr} 17$ is widely deployed in Sichuan wheat cultivars based on marker VENTRIUPLN2 (Gao et al. 2019; Helguera et al. 2003), and as the wheat genotypes carrying these genes also have additional genes for rust resistance, especially HTAP resistance to stripe rust, these resistance sources still can be used in wheat breeding.

Three designated seedling-effective $\mathrm{Lr}$ genes, LrI4a (Dyck and Samborski 1970), Lr14b (Dyck and Samborski 1970), and APR gene Lr68 (Herrera-Foessel et al. 2012), and four Yr APR genes, Yr39 (Lin and Chen 2007), Yr52 (Ren et al. 2012a), Yr59 (Zhou et al. 2014), and $\operatorname{Yr} 67$ (Li et al. 2009), have been reported on chromosome 7BL. $L r 14 a$ and $L r 14 b$ were not effective against the $P t$ races used in the current study, and no data are currently available for $\operatorname{Lr} 68$. QLr.hebau-7BL and QYr.hebau-7BL were detected in 17BDLR and 16CDYR, and both were linked with marker Xcfa2040. The position is similar to Lr68 that is present in CIMMYT line Parula. Hence, QLr.hebau-7BL, present in SW 8588 (a derivative of the CIMMYT line Milan), might be Lr68. This QTL also conferred resistance to stripe rust in the current study, but there is no report to indicate that $\operatorname{Lr68}$ is associated with stripe rust resistance.

$\operatorname{Yr} 39$ is a HTAP resistance gene linked with $\mathrm{Xgwm131}$, which is about $63 \mathrm{cM}$ from QYr.hebau-7BL based on the consensus map
(Somers et al. 2004). The linkage between $\operatorname{Yr} 52$ and $Y r 39$ was $36.5 \pm$ $6.75 \mathrm{cM}$ (Lin and Chen 2007). It is likely that QYr.hebau-7BL is different from $Y r 52$ and $Y r 39$. Yr59 was flanked by markers Xwgp5175 and Xbarc32 at a similar position to QYr.hebau-7BL based on the consensus map (Somers et al. 2004). Yr67 (YrC591) in the Indian cultivar C591 is linked with Xcfa2040 and SCP35M48 which are mapped in a similar position to QYr.hebau$7 B L$. However, both $\operatorname{Yr} 59$ and $\operatorname{Yr} 67$ were described as genes with large effects, whereas $Q Y$ r.hebau- $7 B L$ has a relatively small effect. Therefore, the relationship between $Q Y$ r.hebau-7BL and other resistance genes on chromosome 7BL needs further investigation.

The only leaf rust resistance QTL, QLr.cimmyt-5AL, was previously identified on chromosome 5AL in Avocet (Rosewarne et al. 2012). It was flanked by $w P T-0373$ and $w P T-0837$ and about $2 \mathrm{cM}$ from $\mathrm{Vrn}-\mathrm{Al}$, which is located at $587.0 \mathrm{Mb}$ on the IWGSC RefSeq v1.0 physical map. The position of QLr.hebau-5AL is 589.3 to $591.5 \mathrm{Mb}$ according to the physical positions of the closely linked markers. Although the two QTL were mapped to the similar regions, they appear to have different origins.

Five QTL for stripe rust resistance on chromosome 5A are reported in common wheat varieties; these were present in lines Opata 85 (Boukhatem et al. 2002), Pastor (Rosewarne et al. 2012), Pingyuan 50 (Lan et al. 2010), SHA3/CBRD (Ren et al. 2012b), and Francolin\#1 (Lan et al. 2014). These QTL were located in three different regions of 5A (Rosewarne et al. 2012). The first region is from 558.3 to $562.9 \mathrm{Mb}$, the second from 461.9 to $537.0 \mathrm{Mb}$, and the third from 664.0 to $703.0 \mathrm{Mb}$. It is difficult to determine the relationships between QYr.hebau-5AL (578.2 to $580.4 \mathrm{Mb}$ ) and the QTL in the first region only by chromosome location. QLr.hebau-5AL and $Q Y r$.hebau-5AL were mapped at a similar region, so they might be the same gene with pleiotropic effects for resistance to both leaf rust and stripe rust. Further studies are needed to test this hypothesis.

The APR QTL QLr.hebau-2DS conferring a major resistance effect from Thatcher was detected in all leaf rust environments. Thatcher contains the race-specific APR gene $L r 22 b$ on chromosome 2DS (Dyck 1979), and QLr.hebau-2DS was mapped to the same region according to the physical position of closely linked markers Xgwm296 and Xgwm455. Thatcher showed a susceptible response indicating that $L r 22 b$ was not effective against at least some components of the race mixture used in the field. A minor resistance effect from Thatcher to leaf rust was also observed in another study (Zhang et al. 2017). When the four Pt races (THJS, PGTS, THND, and FHTT) used in the field were separately inoculated on adult plants of Thatcher in the greenhouse, intermediate reactions obtained with PGTS and FHTT indicated that $L r 22 b$ was effective (unpublished data). The MDS for leaf rust on Thatcher in the field tests were about $80 \%$, whereas the frequency distributions extended to $100 \%$. The leaf rust levels on Thatcher could have been lower because part of the inoculum was avirulent.

QLr.hebau-3BL was detected in only one environment. To date, the cataloged $\operatorname{Lr}$ gene, $\operatorname{Lr} 77$ (Kolmer et al. 2018), and two leaf rust

Table 4. Comparison of maximum disease severity scores for leaf and stripe rust among $144 \mathrm{SW} 8588 \times$ Thatcher recombinant inbred lines with and without the resistance alleles

\begin{tabular}{|c|c|c|c|c|c|c|c|c|c|c|}
\hline \multirow[b]{2}{*}{$L r$ locus } & \multirow[b]{2}{*}{ No. ${ }^{y}$} & \multicolumn{3}{|c|}{ Leaf rust } & \multirow[b]{2}{*}{ Yr locus } & \multirow[b]{2}{*}{ No. } & \multicolumn{4}{|c|}{ Stripe rust } \\
\hline & & $\overline{16 B D^{z}}$ & $16 \mathrm{ZK}$ & $\overline{17 B D}$ & & & $\overline{15 C D}$ & $16 \mathrm{CD}$ & 16BD & 17BD \\
\hline -QLr.hebau-1BL & 68 & $55.1 \mathrm{a}$ & $42.9 \mathrm{a}$ & $29.6 \mathrm{a}$ & -QYr.hebau-1BL & 63 & $50.7 \mathrm{a}$ & $56.7 \mathrm{a}$ & $13.1 \mathrm{a}$ & $11.2 \mathrm{a}$ \\
\hline$+Q L r \cdot h e b a u-1 B L$ & 56 & $34.8 \mathrm{~b}$ & $22.4 \mathrm{~b}$ & $15.6 \mathrm{~b}$ & $+Q Y r \cdot h e b a u-1 B L$ & 65 & $27.6 \mathrm{~b}$ & $32.2 \mathrm{~b}$ & $9.8 \mathrm{a}$ & $8.1 \mathrm{a}$ \\
\hline$-L r 37$ & 69 & $52.9 \mathrm{a}$ & $39.8 \mathrm{a}$ & $25.5 \mathrm{a}$ & $-Y r 17$ & 69 & $45.0 \mathrm{a}$ & $54.0 \mathrm{a}$ & $13.9 \mathrm{a}$ & $12.4 \mathrm{a}$ \\
\hline$+\operatorname{Lr} 37$ & 50 & $34.7 \mathrm{~b}$ & $25.9 \mathrm{~b}$ & $19.9 \mathrm{a}$ & $+Y r 17$ & 50 & $30.6 \mathrm{~b}$ & $31.1 \mathrm{~b}$ & $7.8 \mathrm{~b}$ & $5.5 \mathrm{~b}$ \\
\hline -QLr.hebau-5AL & 35 & $49.5 \mathrm{a}$ & $42.4 \mathrm{a}$ & $30.2 \mathrm{a}$ & -QYr.hebau-5AL & 29 & $49.9 \mathrm{a}$ & $59.1 \mathrm{a}$ & $14.7 \mathrm{a}$ & $10.0 \mathrm{a}$ \\
\hline$+Q L r . h e b a u-5 A L$ & 94 & $42.0 \mathrm{a}$ & $29.1 \mathrm{~b}$ & $18.9 \mathrm{a}$ & $+Q Y r \cdot h e b a u-5 A L$ & 103 & $34.8 \mathrm{a}$ & $38.0 \mathrm{~b}$ & $11.2 \mathrm{a}$ & $10.0 \mathrm{a}$ \\
\hline -QLr.hebau-7BL & 65 & $53.2 \mathrm{a}$ & $37.6 \mathrm{a}$ & $34.7 \mathrm{a}$ & -QYr.hebau-7BL & 65 & $44.4 \mathrm{a}$ & $51.8 \mathrm{a}$ & $12.6 \mathrm{a}$ & $12.0 \mathrm{a}$ \\
\hline$+Q L r \cdot h e b a u-7 B L$ & 59 & $37.5 \mathrm{~b}$ & $28.9 \mathrm{a}$ & $9.7 \mathrm{~b}$ & $+Q Y r \cdot h e b a u-7 B L$ & 59 & $33.8 \mathrm{a}$ & $36.8 \mathrm{~b}$ & $11.8 \mathrm{a}$ & $8.4 \mathrm{a}$ \\
\hline -QLr.hebau-2DS & 44 & $63.5 \mathrm{a}$ & $46.3 \mathrm{a}$ & $36.5 \mathrm{a}$ & & & & & & \\
\hline$+Q L r . h e b a u-2 D S$ & 58 & $26.4 \mathrm{~b}$ & $21.0 \mathrm{~b}$ & $13.0 \mathrm{~b}$ & & & & & & \\
\hline
\end{tabular}

${ }^{\mathrm{y}}$ Number of RILs in the population.

${ }^{\mathrm{z}}$ Different letters within columns following the mean indicate significant differences based on Student $t$ tests $(P<0.01)$. 
APR QTL have been mapped on chromosome 3B, including QLr.sfrs-3B (Messmer et al. 2000) and QLr.fcu-3BL (Chu et al. 2009). $L r 77$ is quite effective, so the QTL on $3 B L$ in the current study is likely not $L r 77$, since $Q L r$.hebau- $3 B L$ was effective in only one test. QLr.sfrs-3B detected in the Forno/Oberkulmer RIL population was located at the centromere region (Li et al. 2014). However, $Q L r . f c u-3 B L$ was mapped at $586.5 \mathrm{Mb}$ on $3 \mathrm{BL}$, whereas $Q L r$. hebau-3BL was mapped to the 761.3 to $761.6 \mathrm{Mb}$ region. Hence, QLr.hebau-3BL was different from the two QTL mentioned above and might be a new QTL.

QLr.hebau-6DS was detected in 16ZKLR with 6.3\% PVE. No known QTL for leaf rust resistance was previously documented on chromosome 6DS, and hence QLr.hebau-6DS is new.

Eight APR QTL for stripe rust were previously mapped near the centromere on chromosome 4B (Rosewarne et al. 2013). However, QYr.hebau-4BS was located in the terminal region of 4BS according to the physical locations of the closely linked markers, indicating that the QTL is novel.

QRYr6D.1 was reported on chromosome 6DS flanked by Xgwm325 and Xbarc175 and located at 79.9 to $411.8 \mathrm{Mb}$ (Agenbag et al. 2012). QYr.hebau-6DS in the present study was located at 5.8 to $8.9 \mathrm{Mb}$, thus it is different from QRYr6D.1 and should be a novel QTL for stripe rust resistance.

While some QTL identified in the present study could be novel, they need to be validated in other populations and environments. The genetic distances between the tightly linked SNP or SSR markers and QTL contour peaks ranged from 0.0 to $2.5 \mathrm{cM}$. Some SNP markers identified here are successfully converted to KASP markers (Semagn et al. 2014). These KASP markers can be more efficiently used in marker-assisted selection for pyramiding APR genes in wheat breeding programs to improve the levels of leaf rust and stripe rust resistance.

\section{Acknowledgments}

We thank Prof. R. A. McIntosh, Plant Breeding Institute, University of Sydney for the critical review of this manuscript and for pointing out the possibility that $L r 22 b$ is effective against some components of the Puccinia triticina population in China.

\section{Literature Cited}

Agenbag, G. M., Pretorius, Z. A., Boyd, L. A., Bender, C. M., and Prins, R. 2012. Identification of adult plant resistance to stripe rust in the wheat cultivar Cappelle-Desprez. Theor. Appl. Genet. 125:109-120.

Allen, A. M., Winfield, M. O., Burridge, A. J., Downie, R. C., Benbow, H. R., Barker, G. L. A., Wilkinson, P. A., Coghill, J., Waterfall, C., Davassi, A., Scopes, G., Pirani, A., Webster, T., Brew, F., Bloor, C., Griffiths, S., Bentley, A. R., Alda, M., Jack, P., Phillips, A. L., and Edwards, K. J. 2017. Characterization of a wheat breeders' array suitable for high-throughput SNP genotyping of global accessions of hexaploid bread wheat (Triticum aestivum). Plant Biotechnol. J. 15:390-401.

Bariana, H., and McIntosh, R. 1993. Cytogenetic studies in wheat. XV. Location of rust resistance genes in VPM1 and their genetic linkage with other disease resistance genes in chromosome 2A. Genome 36:476-482.

Boukhatem, N., Baret, P. V., Mingeot, D., and Jacquemin, J. M. 2002. Quantitative trait loci for resistance against yellow rust in two wheat-derived recombinant inbred line populations. Theor. Appl. Genet. 104:111-118.

Cavanagh, C. R., Chao, S., Wang, S., Huang, B. E., Stephen, S., Kiani, S., Forrest, K., Saintenac, C., Brown-Guedira, G. L., Akhunova, A., See, D., Bai, G., Pumphrey, M., Tomar, L., Wong, D., Kong, S., Reynolds, M., Lopez da Silva, M., Bockelman, H., Talbert, L., Anderson, J. A., Dreisigacker, S., Baenziger, S., Carter, A., Korzun, V., Morrell, P. L., Dubcovsky, J., Morell, M. K., Sorrells, M. E., Hayden, M. J., and Akhunov, E. 2013. Genome-wide comparative diversity uncovers multiple targets of selection for improvement in hexaploid wheat landraces and cultivars. Proc. Natl. Acad. Sci. USA 110: 8057-8062.

Chu, C. G., Friesen, T. L., Xu, S. S., Faris, J. D., and Kolmer, J. A. 2009. Identification of novel QTLs for seedling and adult plant leaf rust resistance in a wheat doubled haploid population. Theor. Appl. Genet. 119:263-269.

Cruz, C. D., Peterson, G. L., Bockus, W. W., Kankanala, P., Dubcovsky, J., Jordan, K. W., Akhunov, E., Chumley, F., Baldelomar, F. D., and Valent, B. 2016. The 2NS translocation from Aegilops ventricosa confers resistance to the Triticum pathotype of Magnaporthe oryzae. Crop Sci. 56:990-1000.

Cui, F., Zhang, N., Fan, X., Zhang, W., Zhao, C., Yang, L., Pan, R., Chen, M., Han, J., Zhao, X., Ji, J., Tong, Y., Zhang, H., Jia, J., Zhao, G., and Li, J. 2017. Utilization of a Wheat $660 \mathrm{~K}$ SNP array-derived high-density genetic map for high-resolution mapping of a major QTL for kernel number. Sci. Rep. 7:3788.
Dyck, P. L. 1979. Identification of the gene for adult-plant leaf rust resistance in Thatcher. Can. J. Plant Sci. 59:499-501.

Dyck, P. L., and Samborski, D. J. 1970. The genetics of two alleles for leaf rust resistance at the Lr14 locus in wheat. Can. J. Genet. Cytol. 12:689-694.

Gao, P., Zhou, Y., Gebrewahid, T. W., Zhang, P., Yan, X., Li, X., Yao, Z., Li, Z., and Liu, D. 2019. Identification of known leaf rust resistance genes in common wheat cultivars from Sichuan Province in China. Crop Prot. 115:122-129.

Hayes, H. K., Ausemus, E. R., Stakman, E. C., Bailey, C. H., Wilson, H. K. Bamberg, R. H., Markley, M. C., Crim, R. F., and Levine, M. N. 1936. Thatcher wheat. Minn. Agric. Exp. Stn. Tech. Bull. 325. 39 pp. https:// conservancy.umn.edu/bitstream/handle/11299/163794/mn-ext-bltn-325.pdf? sequence $=1$

Helguera, M., Khan, I. A., Kolmer, J., Lijavetzky, D., Zhong-qi, L., and Dubcovsky, J. 2003. PCR assays for the Lr37-Yr17-Sr38 cluster of rust resistance genes and their use to develop isogenic hard red spring wheat lines. Crop Sci. 43:1839-1847.

Herrera-Foessel, S. A., Singh, R. P., Huerta-Espino, J., Rosewarne, G. M., Periyannan, S. K., Viccars, L., Calvo-Salazar, V., Lan, X. C., and Lagudah, E. S. 2012. Lr68: A new gene conferring slow rusting resistance to leaf rust in wheat. Theor. Appl. Genet. 124:1475-1486.

Herrera-Foessel, S. A., Singh, R. P., Lillemo, M., Huerta-Espino, J., Bhavani, S., Singh, S., Lan, C. X., Calvo-Salazar, V., and Lagudah, E. S. 2014. Lr67/Yr46 confers adult plant resistance to stem rust and powdery mildew in wheat. Theor. Appl. Genet. 127:781-789.

Johnson, R. 1988. Durable resistance to yellow (stripe) rust in wheat and its implications in plant breeding. In: Breeding Strategies for Resistance to the Rusts of Wheat, El Batan, Mexico (Mexico), 29 Jun-1 Jul 1987. CIMMYT.

Knott, D. R. 1989. The wheat rusts - breeding for resistance. Monographs on Theor. Appl. Genet. No. 12. Springer-Verlag, Berlin.

Kolmer, J. A., Su, Z., Bernardo, A., Bai, G., and Chao, S. 2018. Mapping and characterization of the new adult plant leaf rust resistance gene $\operatorname{Lr} 77$ derived from Santa Fe winter wheat. Theor. Appl. Genet. 131:1553-1560.

Kosambi, D. D. 1943. The estimation of map distance from recombination values. Ann. Eugen. 12:172-175.

Lagudah, E. S. 2011. Molecular genetics of race non-specific rust resistance in wheat. Euphytica 179:81-91.

Lan, C., Liang, S., Zhou, X., Zhou, G., Lu, Q., Xia, X., and He, Z. 2010 Identification of genomic regions controlling adult-plant stripe rust resistance in Chinese landrace Pingyuan 50 through bulked segregant analysis. Phytopathology 100:313-318.

Lan, C., Rosewarne, G. M., Singh, R. P., Herrera-Foessel, S. A., Huerta-Espino, J., Basnet, B. R., Zhang, Y., and Yang, E. 2014. QTL characterization of resistance to leaf rust and stripe rust in the spring wheat line Francolin\#1. Mol. Breed. 34: 789-803.

Li, H. H., Ye, G. Y., and Wang, J. K. 2007. A modified algorithm for the improvement of composite interval mapping. Genetics 175:361-374.

Li, Y., Niu, Y. C., and Chen, X. M. 2009. Mapping a stripe rust resistance gene YrC591 in wheat variety C591 with SSR and AFLP markers. Theor. Appl. Genet. 118:339-346.

Li, Z., Lan, C., He, Z., Singh, R. P., Rosewarne, G. M., Chen, X., and Xia, X. 2014. Overview and application of QTL for adult plant resistance to leaf rust and powdery mildew in wheat. Crop Sci. 54:1907-1925.

Lin, F., and Chen, X. M. 2007. Genetics and molecular mapping of genes for racespecific all-stage resistance and non-race-specific high-temperature adult-plant resistance to stripe rust in spring wheat cultivar Alpowa. Theor. Appl. Genet. 114:1277-1287

Liu, L., Wang, M. N., Feng, J. Y., See, D. R., Chao, S. M., and Chen, X. M. 2018 Combination of all-stage and high-temperature adult-plant resistance QTL confers high level, durable resistance to stripe rust in winter wheat cultivar Madsen. Theor. Appl. Genet. 131:1835-1849.

McIntosh, R. A., Dubcovsky, J., Rogers, W. J., Morris, C., and Xia, X. C. 2017 Catalogue of gene symbols for wheat: 2017 supplement. Available at: https:// shigen.nig.ac.jp/wheat/komugi/genes/macgene/supplement2017.pdf

McIntosh, R. A., Wellings, C. R., and Park, R. F. 1995. Wheat rusts: An atlas of resistance genes. CSIRO Australia, Sydney. Kluwer Academic Publishers, Dordrecht, the Netherlands.

McNeal, F. H., Konzak, C. F., Smith, E. P., Tate, W. S., and Russell, T. S. 1971: Pages 34-121 in: A uniform system for recording and processing cereal research data. U.S. Dep. Agric. Agric. Res. Serv. Bull.

Messmer, M. M., Seyfarth, R., Keller, M., Schachermayr, G., Winzeler, M., Zanetti, S., Feuillet, C., and Keller, B. 2000. Genetic analysis of durable leaf rust resistance in winter wheat. Theor. Appl. Genet. 100:419-431.

Milus, E. A., Lee, K. D., and Brown-Guedira, G. 2015. Characterization of stripe rust resistance in wheat lines with resistance gene $\operatorname{Yr} 17$ and implications for evaluating resistance and virulence. Phytopathology 105:1123-1130.

Peterson, R. F., Campbell, A. B., and Hannah, A. E. 1948. A diagrammatic scale for estimating rust intensity on leaves and stems of cereals. Can. J. Res. 26:496-500

Qureshi, N., Bariana, H., Kumran, V. V., Muruga, S., Forrest, K. L., Hayden, M. J. and Bansal, U. 2018. A new leaf rust resistance gene $\operatorname{Lr} 79$ mapped in chromosome 3BL from the durum wheat landrace Aus26582. Theor. Appl. Genet. 131:1091-1098.

Ramirez-Gonzalez, R. H., Uauy, C., and Caccamo, M. 2015. PolyMarker: A fast polyploid primer design pipeline. Bioinformatics 31:2038-2039. 
Ren, R. S., Wang, M. N., Chen, X. M., and Zhang, Z. J. 2012a. Characterization and molecular mapping of $Y r 52$ for high-temperature adult-plant resistance to stripe rust in spring wheat germplasm PI 183527. Theor. Appl. Genet. 125: 847-857.

Ren, Y., He, Z., Li, J., Lillemo, M., Wu, L., Bai, B., Lu, Q., Zhu, H., Zhou, G., Du, J., Lu, Q., and Xia, X. 2012b. QTL mapping of adult-plant resistance to stripe rust in a population derived from common wheat cultivars Naxos and Shanghai 3/Catbird. Theor. Appl. Genet. 125:1211-1221.

Röder, M. S., Korzun, V., Wendehake, K., Plaschke, J., Tixier, M. H., Leroy, P., and Ganal, M. W. 1998. A microsatellite map of wheat. Genetics 149: 2007-2023.

Roelfs, A. P., Singh, R. P., and Saari, E. E. 1992. Rust diseases of wheat: Concepts and methods of disease management. Texcoco. CIMMYT

Rosewarne, G. M., Herrera-Foessel, S. A., Singh, R. P., Huerta-Espino, J., Lan, C. X., and He, Z. H. 2013. Quantitative trait loci of stripe rust resistance in wheat. Theor. Appl. Genet. 126:2427-2449.

Rosewarne, G. M., Singh, R. P., Huerta-Espino, J., Herrera-Foessel, S. A., Forrest, K. L., Hayden, M. J., and Rebetzke, G. J. 2012. Analysis of leaf and stripe rust severities reveals pathotype changes and multiple minor QTLs associated with resistance in an Avocet×Pastor wheat population. Theor. Appl. Genet. 124: 1283-1294.

Semagn, K., Babu, R., Hearne, S., and Olsen, M. 2014. Single nucleotide polymorphism genotyping using Kompetitive Allele Specific PCR (KASP): Overview of the technology and its application in crop improvement. Mol. Breed. 33:1-14.

Sharp, P. J., Kreis, M., Shewry, P. R., and Gale, M. D. 1988. Location of $\beta$-amylase sequences in wheat and its relatives. Theor. Appl. Genet. 75:286-290.

Singh, A., Pandey, M. P., Singh, A. K., Knox, R. E., Ammar, K., Clarke, J. M., Singh, R. P., Pozniak, C. J., DePauw, R. M., McCallum, B. D., Cuthbert, R. D., Randhawa, H. S., and Fetch, T. G., Jr. 2013. Identification and mapping of leaf, stem and stripe rust resistance quantitative trait loci and their interactions in durum wheat. Mol. Breed. 31:405-418.

Singh, R. P., Nelson, J. C., and Sorrells, M. E. 2000. Mapping Yr28 and other genes for resistance to stripe rust in wheat. Crop Sci. 40:1148-1155.

Somers, D. J., Isaac, P., and Edwards, K. 2004. A high-density microsatellite consensus map for bread wheat (Triticum aestivum L.). Theor. Appl. Genet. 109:1105-1114.
Voorrips, R. E. 2002. MapChart: Software for the graphical presentation of linkage maps and QTLs. Heredity 93:77-78.

Wan, A. M., Chen, X. M., and He, Z. H. 2007. Wheat stripe rust in China. Aust. J. Agric. Res. 58:605-619.

Wang, S., Wong, D., Forrest, K., Allen, A., Chao, S., Huang, B. E., Maccaferri, M., Salvi, S., Milner, S. G., Cattivelli, L., Mastrangelo, A. M., Whan, A., Stephen, S., Barker, G., Wieseke, R., and Plieske, J. 2014. Characterization of polyploid wheat genomic diversity using a high-density 9000 single nucleotide polymorphism array. Plant Biotechnol. J. 12:787-796.

Wellings, C. R. 2011. Global status of stripe rust: A review of historical and current threats. Euphytica 179:129-141.

Winfield, M. O., Allen, A. M., Burridge, A. J., Barker, G. L., Benbow, H. R., Wilkinson, P. A., Coghill, J., Waterfall, C., Davassi, A., Scopes, G., Pirani, A., Webster, T., Brew, F., Bloor, C., King, J., West, C., Griffiths, S., King, I., Bentley, A. R., and Edwards, K. J. 2016. High-density SNP genotyping array for hexaploid wheat and its secondary and tertiary gene pool. Plant Biotechnol. J. 14:1195-1206.

Xie, S. X., Wu, L. R., Yang, S. L., and Wang, K. N. 1990. Epidemic problems and control measures of wheat stripe rust in China. Plant Prot. 16:43-45.

Yu, H., Xie, W., Wang, J., Xing, Y., Xu, C., Li, X., Xiao, J., and Zhang, Q. 2011. Gains in QTL detection using an ultra-high density SNP map based on population sequencing relative to traditional RFLP/SSR markers. PLoS One 6:e17595.

Zadoks, J. C., Chang, T. T., and Konzak, C. F. 1974. A decimal code for the growth stages of cereals. Weed Res. 14:415-421.

Zhang, P., Qi, A., Zhou, Y., Xia, X., He, Z., Li, Z., and Liu, D. 2017. Quantitative trait loci mapping of adult-plant resistance to leaf rust in a Fundulea 900×'Thatcher' wheat cross. Plant Breed. 136:1-7.

Zhang, Z., Ji, H., Shen, L., Xu, S., Ni, J., and Peng, Y. 2012. Postulation of resistance genes and evaluation of adult resistance to stripe rust in 58 cultivars from Sichuan. Acta Phytophylac. Sin. 39:12-23.

Zhou, H., Xia, X., He, Z., Li, X., Wang, C., Li, Z., and Liu, D. 2013. Molecular mapping of leaf rust resistance gene $L r N J 97$ in Chinese wheat line Neijiang 977671. Theor. Appl. Genet. 126:2141-2147.

Zhou, X. L., Wang, M. N., Chen, X. M., Lu, Y., Kang, Z. S., and Jing, J. X. 2014 Identification of $\operatorname{Yr} 59$ conferring high-temperature adult-plant resistance to stripe rust in wheat germplasm PI 178759. Theor. Appl. Genet. 127:935-945. 